\title{
The European Brain Injury Consortium Survey of Head Injuries
}

\author{
G. D. Murray ${ }^{1}$, G. M. Teasdale ${ }^{2}$, R. Braakman ${ }^{3}$, F. Cohadon $^{4}$, M. Dearden ${ }^{5}$, F. Iannotti $^{6}$, A. Karimi ${ }^{7}$, \\ F. Lapierre ${ }^{8}$, A. Maas $^{9}$, J. Ohman ${ }^{10}$, L. Persson ${ }^{11}$, F. Servadei ${ }^{12}$, N. Stocchetti ${ }^{13}$, T. Trojanowski ${ }^{14}$, \\ and A. Unterberg ${ }^{15}$ on behalf of the European Brain Injury Consortium
}

${ }^{1}$ Medical Statistics Unit, University of Edinburgh Medical School, Edinburgh, U.K.

${ }^{2}$ University Department of Neurosurgery, Institute of Neurological Sciences, Southern General Hospital, Glasgow, U.K.

${ }^{3}$ Berkel Enschot, The Netherlands

${ }^{4}$ Department of Neurosurgery, Hospital Pellegrin, Bordeaux, France

${ }^{5}$ Department of Anaesthetics, Leeds General Infirmary, Leeds, U.K.

${ }^{6}$ Department of Clinical Neurosciences, Southampton General Hospital, Southampton, U.K.

${ }^{7}$ Neurochirurgische Klinik, Universität Köln, Köln, Federal Republic of Germany

${ }^{8}$ Centre Hospitalier Universitaire de Poitiers, Service de Neurochirurgie, Poitiers, France

${ }^{9}$ Department of Neurosurgery, University Hospital Rotterdam, Rotterdam, The Netherlands

${ }^{10}$ Department of Neurosurgery, Helsinki University Central Hospital, Helsinki, Finland

${ }^{11}$ Department of Neurosurgery, Akademiska Hospital, Uppsala, Sweden

${ }^{12}$ Divisione di Neurochirurgica, Ospedale M. Bufalini, Cesena, Italy

${ }^{13}$ Terapia Intensiva Neurochirurgica Servizio Anestesia e Rianimazione, Ospedale Maggiore Policlinico, IRCCS Milano, Milano, Italy

${ }^{14}$ Department of Neurosurgery, University Medical School, Lublin, Poland

${ }^{15}$ Department of Neurosurgery, Virchow-Klinikum, Medizinische Fakultät, Humboldt Universität Berlin, Berlin, Federal Republic of Germany

\section{Summary}

To provide a picture of contemporary practice, a survey was carried out of severely and moderately head injured patients admitted to 67 'neuro' centres in 12 European countries. 1,005 adult head injuries were recruited over a three month period. Sixty items of information on demography, clinical features, investigations, management and early complications were captured on a simple, two-page questionnaire and, information on outcome at six months on a third page.

The median age of the subjects was 38 years, $74 \%$ were male and $51 \%$ injured in road traffic accidents; $57 \%$ of patients were transferred to the 'neuro' centre from another hospital. Assessment of clinical responsiveness was limited by the use of sedation and intubation and information from four early time points (pre-hospital, arrival at the Accident and Emergency department, post-resuscitation, and arrival at the 'neuro' unit) was combined to stratify the subjects as severe $(58 \%)$, moderate $(17 \%)$ or intermediate $(19 \%)$. In $48 \%$ of patients classified the CT scan showed features of a 'mass lesion' and in $40 \%$ showed a subarachnoid haemorrhage. Fifty-five centres provided the data on outcome for $94 \%$ of the cases recruited in these centres six months after injury. $31 \%$ died, $3 \%$ were vegetative, $16 \%$ severely disabled, $20 \%$ moderately disabled and $31 \%$ had made a good recovery. Comparison of the data from different parts of Europe showed differences in the frequency of secondary transfer, cause of injury, occurrence of major extracranial injury, CT scan findings, intracranial operation, clinical severity of injury and utilisation of the components of intensive care and the occurrence of a favourable outcome, although the latter difference was not statisti- cally significant when variations in the initial severity of injury were taken into account.

The findings in the present survey are compared with newly analysed information for three previous large series: the International Data Bank involving the UK, the Netherlands and the USA, the North American Traumatic Coma Data Bank, and data from four centres in the UK. The comparisons showed substantial similarities and also differences that may reflect variations in policy for admission of the head injury to 'neuro' units, and evolution in methods of assessment, investigation and management. The effects of these differences on outcome requires further, rigorous prospective study.

Keywords: Head injury; European survey; management; outcome.

\section{Introduction}

The European Brain Injury Consortium (EBIC) is a network of European units, experienced in the care of head injured patients, and was formally constituted in 1995 [38]. The Consortium promotes international, multicentre, interdisciplinary research aimed at improving the outcome of patients who have suffered a head injury or other kind of acute brain damage. During the formal establishment of EBIC, it was de- 
cided to conduct a survey of head injured patients in the interested centres.

The survey had three purposes. First, the exercise would test if it was possible to collect comprehensive, credible data through an organisation with strong commitment but only modest resources. Second, the results would be of considerable intrinsic interest and importance: existing comprehensive databases on severe head injury are over a decade old $[9,15,23,28]-$ and more recent reports concern only selected populations entered into clinical trials. The survey therefore would provide a unique picture of contemporary practice in different parts of Europe and how the findings related to previous data. Third, the results would be invaluable for conducting 'what if?' evaluations of potential inclusion/exclusion criteria for formal clinical studies and trials, for example, the proportion of severe head injuries who are admitted to a neurosurgical unit within different times of injury, or with different clinical states and how they are currently managed, and how these factors influence the outcome expected with 'conventional' treatment.

In this paper we describe the features of the 1005 adult patients, considered to have a severe or moderate head injury, reported to the European Core Data Bank, and compare the findings in different groups of subjects and in different parts of Europe. The results of the present series are compared to previous reports of multicentre series collected prospectively in routine clinical practice. Problems, identified in the current series in defining clinical severity of the injury, are addressed in relation to previous experience. The findings in the more selected populations customarily recruited to trials of pharmacological agents are considered in a separate paper [20].

\section{Methods}

A two page questionnaire was designed to capture 60 items of information on demography, clinical features, investigations, management, complications and early outcome. The first page covered the first day following the injury, and included age; sex; cause of injury; mode of admission to the neurosurgical hospital (direct or transfer); timing of injury, admission to first hospital and admission to the neurosurgical hospital; details of any extracranial injuries; clinical evidence of severity of injury was assessed by the Glasgow Coma Scale (GCS) [39] and pupil response to light. Data were recorded at four stages: 1. pre-hospital (ie the first reliable observation made by a 'paramedic' or medical staff); 2 . arrival at the Accident and Emergency Department of the hospital where the patient was first taken; 3. post resuscitation (ie the state after initial resuscitation); 4. neuro unit (ie the point at which the patient comes under specialist, usually neurosurgical, care but also neurointensive and neurological). Features such as early complications (hypoxia, hypotension or hypothermia); the results of an admission CT scan; details of any intracranial operation within the first 24 hours and of any emergency extracranial operations were also covered. The second page covered the hospital care up to discharge from the neurosurgical hospital and included details of management and monitoring (intracranial pressure monitoring, ventilation, jugular $\mathrm{SVO}_{2}$ monitoring, invasive blood pressure monitoring); the results of a final CT scan; details of any intracranial complications which required treatment (delayed haematoma, raised ICP, meningitis/ ventriculitis, seizures); details of any life threatening systemic complications (respiratory, cardiovascular, metabolic, infection); timing and mode of discharge; and cause of death where applicable.

\section{Patient Inclusion}

The data collection exercise ran from 1st of February 1995 to 30th of April 1995. All centres that had, at that time, expressed interest in EBIC were invited to participate and were asked to return details of all moderate or severe adult ( $>16$ years) head injuries admitted to their care within 24 hours of injury. Patients were to be included if their Glasgow Coma Score [40] was 12 or less at any of the four stages described above, this corresponds to previous definitions of severe (GCS 3 to $8[9,23]$ ) and moderate (GCS 9-12 [34]) head injuries.

Data relating to the first 24 hours following injury were to be returned to the EBIC Co-ordination Centre by mail or fax within one week of admission, and the discharge forms were sent in batches at the end of each month. After the collection of the initial data was completed, centres were contacted to ask for details of each patient's outcome six months following their injury. For this, a third, one page questionnaire was designed which gathered information on whether the patient was alive at six months and, if so, the status on the Glasgow Outcome Scale [14]. The GOS is generally accepted as a valid measure of outcome after head injury, with adequate observer reliability [21]. General definitions on outcome categories were provided to centres, but assignment of subjects was not based on a structured interview as has recently been proposed by Wilson et al. [44]. An individual form was prepared for each patient in the survey, and these forms were sent to centres for completion.

The entire survey was designed to be conducted on a very limited budget. In particular, there were no resources for additional research assistants, or for site visits to check data against source records. The monitoring was limited to checking the forms as they were received at the EBIC Co-ordinating Centre, and any inconsistencies in the data were queried with the relevant centres. On completion of the data collection, a report was generated which was tailored for each individual centre. This reported detailed results for that centre, together with results for the relevant country and for the entire series, and gave an opportunity for the centres themselves to raise queries with the data.

\section{Results}

\section{Response Rate}

Core Data forms were sent to 104 centres, and of these $67(64 \%)$ in twelve countries returned data on a total of 1005 adult head injuries. Forty seven $(5 \%)$ of the cases were injured just outside the three month window set for the survey but are included and this report gives results for all 1005 cases. Table 1 gives the 
Table 1. Summary of Cases Reported

\begin{tabular}{llc}
\hline Country & Number of centres & Number of cases \\
\hline Germany & 19 & 241 \\
United Kingdom & 15 & 219 \\
Italy & 10 & 184 \\
France & 4 & 95 \\
Spain & 3 & 90 \\
The Netherlands & 4 & 58 \\
Sweden & 4 & 46 \\
Finland & 1 & 19 \\
Switzerland & 2 & 18 \\
Denmark & 2 & 15 \\
Yugoslavia & 1 & 11 \\
Belgium & 2 & 9 \\
Total & 67 & 1005 \\
\hline
\end{tabular}

numbers of centres and the number of cases per country, with the countries ordered by number of cases.

\section{Demographics}

Differences in patient demographics, treatments, complications and outcomes between various regions were analyzed with the chi-squared test.

The patterns of age (mean 42, median 38 years), sex ( $74 \%$ male) and cause of injury (51\% some type of road traffic accident) are shown in Table 2.

\section{Referral to "Neuro" Unit}

Only $43 \%$ of patients were admitted directly to a hospital with neurosurgical facilities, the remaining $57 \%$ were transferred secondarily from another hospital. Patients admitted directly to the hospital containing the neurotrauma unit took rather longer to reach hospital (median 45 minutes) compared to those admitted to another hospital for assessment before transfer (median 35 minutes). On the other hand, direct admission to a hospital with a neurotrauma unit was associated with a shorter time from injury to the patient coming under specialist care (median 1 hour) in contrast with a median of four hours for patients transferred from another hospital. Such direct admission was the rule in Spain and the Benelux countries, whereas secondary transfer was the rule in the UK, France and Scandinavia, with Italy and Germany occupying intermediate positions.

\section{Clinical Assessment}

Assessment of the components of the Glasgow Coma Scale was limited by widespread use of sedation
Table 2. Features of Patients Reported to the European Brain Injury Consortium Core Data Survey

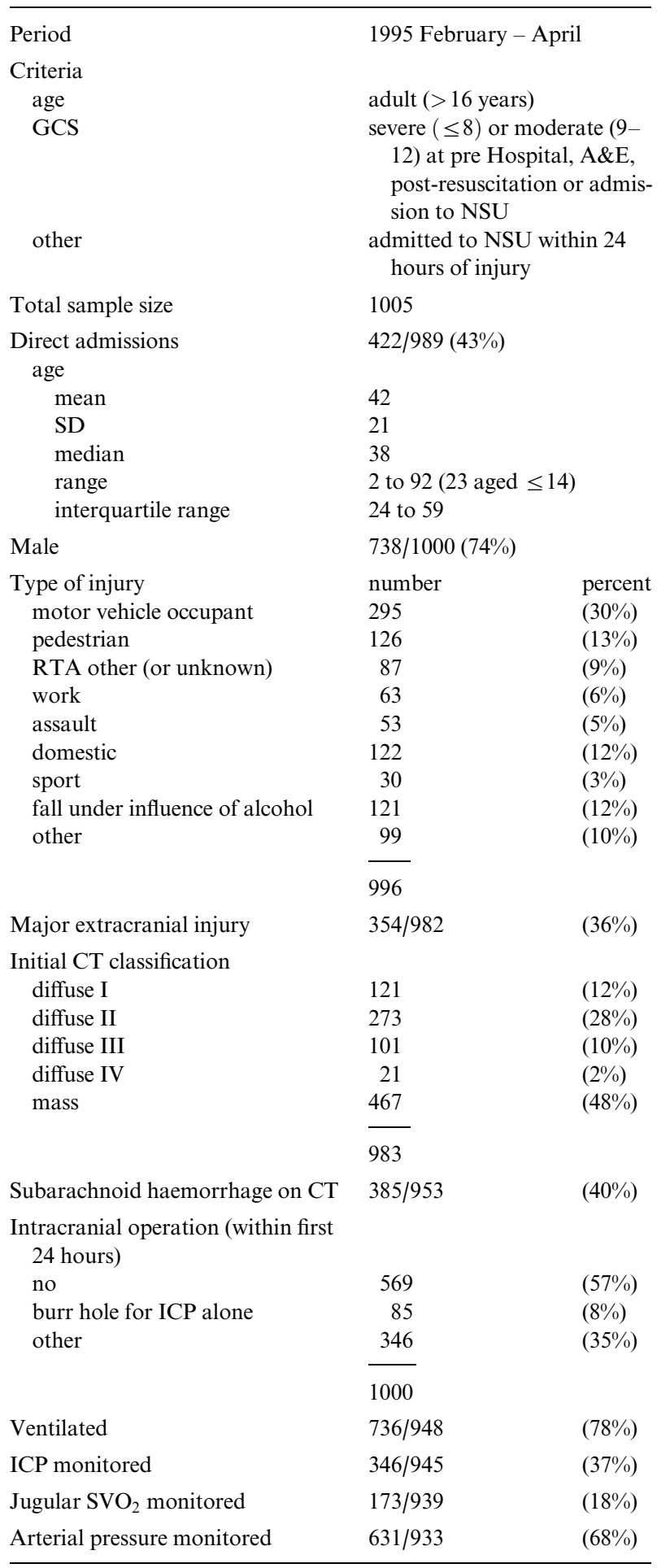

and intubation. Table 3 summarises the proportion of cases where GCS was recorded at different time points (including situations where the GCS was recorded as 'untestable'), and those where GCS could be assessed. 
Table 3. Availability of Glasgow Coma Scale at Different Stages in the Early Triage and Management of Head Injured Patients

\begin{tabular}{lllll}
\hline & Pre-hospital & A\&E department & 'Post-resuscitation' & Admission to neurosurgery \\
\hline GCS motor score recorded & $65 \%$ & $89 \%$ & $76 \%$ & $94 \%$ \\
GCS motor score testable & $62 \%$ & $82 \%$ & $62 \%$ & $72 \%$ \\
Full GCS recorded & $65 \%$ & $89 \%$ & $75 \%$ & $93 \%$ \\
Full GCS testable & $61 \%$ & $77 \%$ & $49 \%$ & $56 \%$ \\
\hline
\end{tabular}

Twenty-four percent of cases were recorded as obeying commands according to the GCS motor score on at least one of the four assessments.

At time of admission to the Neurosurgical Unit, GCS was $\leq 8$ in 329 subjects, 9-12 in 162 subjects and $13-15$ in 75 subjects, the GCS was untestable in 371 subjects and not recorded in 68 subjects.

\section{Admission CT Findings}

The appearances on the first $\mathrm{CT}$ scan after admission were classified according to the Traumatic Coma Data Bank (TCDB) categories [26]. Twelve percent were class I (normal), $28 \%$ class II (diffuse injury), $10 \%$ class III (diffuse injury with swelling), $2 \%$ class IV (diffuse injury with shift), and $48 \%$ were classified as having a 'mass' lesion. Subarachnoid haemorrhage was identified in $40 \%$ of cases and intraventricular haemorrhage was identified in $14 \%$ of cases. In total 897 patients had data on a further 'final' or 'worst' CT scan as well as their admission scan, and these data are being presented fully in a separate report.

\section{Early Complications}

Twenty percent of patients were recorded as having minor extracranial injuries, and 36\% were recorded as having major extracranial injuries, defined as an injury which in itself would have required hospital admission. Fourteen percent of all cases underwent an emergency extracranial operation. Early complications were recorded as hypoxia $(27 \%)$, hypotension $(22 \%)$ and hypothermia $(6 \%)$, and $35 \%$ of patients underwent an intracranial operation (other than the placement of an ICP catheter or transducer) within the first 24 hours following injury.

\section{Management and Monitoring}

Ventilation was used in $78 \%$ of patients, ICP, jugular $\mathrm{SVO}_{2}$ and invasive blood pressure monitoring were used respectively in $37 \%, 18 \%$ and $68 \%$ of patients.

\section{Delayed Complications}

Intracranial infection was reported in 8 patients $(1 \%)$, and other intracranial complications of delayed haematoma (after 24 hours), raised ICP and seizures were reported respectively in $11 \%, 28 \%$ and $7 \%$ of patients. Life threatening systemic complications classified as respiratory, cardiovascular, metabolic and infection were reported respectively for $24 \%, 12 \%, 5 \%$ and $13 \%$ of subjects.

\section{Outcome at six Months}

Fifty five centres provided data on Glasgow Outcome Score (GOS) at six months for 796 subjects. These were $94 \%$ of the 847 cases initially reported from these centres. One hundred and fifty eight $(76 \%)$ of the remaining 209 cases without data on six month GOS came from 12 centres which were unable to supply any data on six month outcome in any patient. Therefore, in the 55 centres able to provide information on six month outcome, the data were $94 \%$ complete. The features of the cases in the 12 centres that did not provide outcome data were broadly similar to those in the 55 centres reporting outcome. Furthermore, in the latter centres, the initial features of the cases with and without outcome data were very similar.

Of the 796 patients whose GOS was available at six months, $244(31 \%)$ were dead, $20(3 \%)$ vegetative, 124 $(6 \%)$ severely disabled, $159(20 \%)$ moderately disabled, and $249(31 \%)$ were considered to have made a good recovery. Thus, the combination of the last two groups into a 'favourable' outcome occurred in 51\%.

\section{Severity Subsets}

The criteria for inclusion of patients included patients with 'moderate' (GCS 9-12) as well as severe $(\mathrm{GCS} \leq 8)$ head injuries. Identification of severe cases was complicated by the variability in data available at the various initial time points, in particular data being 'missing' because of intubation, paralysis and ventilation. For comparisons within this survey and with previous series we identified three subsets of patients: 
Table 4. Outcome at Six Months in Subjects Grouped by 'Overall' Initial Severity. Severity Subsets were Defined from Data at all 4 Early Points (see Text). Figures are Numbers of Subjects (\%)

\begin{tabular}{lcccccc}
\hline Severity subset & Total & Dead & Vegetative & Severe disability & Moderate disability & Good recovery \\
\hline Severe & 481 & $192(40 \%)$ & $17(4 \%)$ & $78(16 \%)$ & $93(19 \%)$ & $101(21 \%)$ \\
Intermediate & 145 & $32(22 \%)$ & $2(1 \%)$ & $20(14 \%)$ & $27(19 \%)$ & $64(44 \%)$ \\
Moderate & 128 & $11(9 \%)$ & $0(0 \%)$ & $18(14 \%)$ & $31(24 \%)$ & $68(53 \%)$ \\
Unclassified & 42 & $9(21 \%)$ & $1(2 \%)$ & $8(19 \%)$ & $8(19 \%)$ & $16(38 \%)$ \\
\hline
\end{tabular}

Severe cases $(\mathrm{n}=583)$ were composed of: a) all those with GCS 3-8 on admission to the neurosurgical unit (NSU) $(\mathrm{n}=329)$, b) those other patients whose GCS at admission to NSU was untestable or not recorded and who had at least one previous observation of a GCS 3-8 and none of a higher GCS $(\mathrm{n}=254)$.

The moderate group had a GCS of $\geq 9$ on admission to NSU and no other recording of a GCS of $<9$ $(\mathrm{n}=171)$.

A third group of 'intermediate' severity cases $(\mathrm{n}=192)$ did not have a GCS of 3-8 at admission to NSU but had, on other occasions at least one GCS of 3-8 and at least one of $\geq 9$. In 59 patients there were insufficient data on GCS to make any sensible classification.

Patients classified as severe in this way, in comparison with the pooled intermediate and moderate groups, were younger (median age 34 years versus 42 years), more often a vehicle occupant (35\% versus $21 \%$ ) more often admitted directly to a hospital with a neuro unit ( $45 \%$ versus $40 \%$ ), had a higher frequency of major extracranial injury ( $41 \%$ versus $28 \%$ ), of an intracranial operation in the first 24 hours $(37 \%$ versus $30 \%)$, and their CT scans were less often normal $(10 \%$ versus $16 \%$ ) and more often showed diffuse swelling (13\% versus $6 \%)$ or traumatic subarachnoid haemorrhage $(47 \%$ versus $32 \%)$. They were more often ventilated $(92 \%$ versus $56 \%$ ), had invasive monitoring of blood pressure ( $80 \%$ versus $48 \%$ ), or intracranial pressure $(43 \%$ versus $24 \%)$. Thirty six percent of the severe group had bilateral non-reacting pupils at admission to NSU, in comparison with $7 \%$ for the intermediate/ moderate groups. The outcomes in these groups are shown in Table 4 . The proportions with a 'favourable' outcome at six months were: severe, $40 \%$; intermediate, $63 \%$; moderate, $77 \%$; and unclassified, $57 \%$.

\section{Comparison of Data from Different Areas of Europe}

There were data from a sufficient number of subjects for a country based analysis in only some cases (ie
Germany, UK, Italy, France and Spain), and other countries were grouped arbitrarily by region of Europe (Scandinavia and Benelux). There were no major differences in the data from these areas for subjects' ages or sex distribution but several differences in distribution that were significantly different were noted (Table 5).

1. The frequency of secondary transfer to the hospital with the neuro unit ranged from $35 \%$ in the Benelux countries to $75 \%$ in the UK $(\mathrm{p}<0.001)$.

2. There were substantial differences amongst countries in the cause of injury $(\mathrm{p}<0.001)$. The proportion who were injured as a vehicle occupant ranged from $11 \%$ in the UK to $48 \%$ in the Benelux countries, and of those who fell under the influence of alcohol from 1\% in Spain to 33\% in Scandinavia.

3. The proportion of the subjects with a major extracranial injury ranged from $24 \%$ in Scandinavia to $53 \%$ in the Benelux countries $(\mathrm{p}<0.001)$.

4. There were marked differences in admission CT findings amongst the countries $(\mathrm{p}<0.001)$. The proportion of patients with a normal CT scan ranged from $4 \%$ in Scandinavia to $10 \%$ in France, and those with swelling from $7 \%$ in Spain to $18 \%$ in Italy. The proportions with subarachnoid haemorrhage ranged from $33 \%$ in the UK to $57 \%$ in Spain $(\mathrm{p}<0.001)$.

5. The proportion of the subjects who had an intracranial operation in the first 24 hours ranged from $18 \%$ in the Benelux to $53 \%$ in Germany $(\mathrm{p}<0.001)$.

6. The frequency of the use of ventilation ranged from $53 \%$ of subjects in France to $88 \%$ in Germany, of invasive blood pressure monitoring from $31 \%$ in France to $89 \%$ in Scandinavia and of intracranial pressure monitoring from $5 \%$ in France to $53 \%$ in Spain ( $p<0.001$ in each case).

7. The proportion of subjects with a severe injury (as defined above from the data available on GCS at the four early time points) ranged from $42 \%$ in the 
Table 5. Comparison of Features of the Patients from Different Parts of Europe

\begin{tabular}{|c|c|c|c|c|c|c|c|}
\hline & Germany & UK & Italy & France & Spain & Scandinavia & $\begin{array}{l}\text { Benelux } \\
\text { countries }\end{array}$ \\
\hline Sample size & 241 & 219 & 184 & 95 & 90 & 80 & 67 \\
\hline Indirect transfer & $50 \%$ & $75 \%$ & $56 \%$ & $66 \%$ & $41 \%$ & $65 \%$ & $35 \%$ \\
\hline Age (median) & 41 & 38 & 35 & 39 & 35 & 41 & 32 \\
\hline Male & $68 \%$ & $78 \%$ & $78 \%$ & $69 \%$ & $76 \%$ & $79 \%$ & $68 \%$ \\
\hline \multicolumn{8}{|l|}{ Type of injury } \\
\hline vehicle occupant & $27 \%$ & $11 \%$ & $42 \%$ & $26 \%$ & $43 \%$ & $31 \%$ & $46 \%$ \\
\hline fall & $14 \%$ & $20 \%$ & $2 \%$ & $11 \%$ & $1 \%$ & $33 \%$ & $4 \%$ \\
\hline Major extracranial injury & $31 \%$ & $27 \%$ & $52 \%$ & $26 \%$ & $52 \%$ & $24 \%$ & $53 \%$ \\
\hline \multicolumn{8}{|l|}{ Initial CT scan findings } \\
\hline normal & $10 \%$ & $16 \%$ & $12 \%$ & $16 \%$ & $13 \%$ & $4 \%$ & $11 \%$ \\
\hline swelling & $10 \%$ & $11 \%$ & $18 \%$ & $4 \%$ & $4 \%$ & $8 \%$ & $11 \%$ \\
\hline subarachnoid haemorrhage & $34 \%$ & $23 \%$ & $56 \%$ & $50 \%$ & $57 \%$ & $39 \%$ & $42 \%$ \\
\hline Intracranial operation within 24 hours & $53 \%$ & $25 \%$ & $27 \%$ & $23 \%$ & $33 \%$ & $49 \%$ & $18 \%$ \\
\hline Ventilation & $88 \%$ & $68 \%$ & $82 \%$ & $53 \%$ & $87 \%$ & $87 \%$ & $75 \%$ \\
\hline Blood pressure monitoring & $77 \%$ & $60 \%$ & $72 \%$ & $31 \%$ & $72 \%$ & $89 \%$ & $75 \%$ \\
\hline ICP monitoring & $37 \%$ & $37 \%$ & $35 \%$ & $6 \%$ & $53 \%$ & $52 \%$ & $39 \%$ \\
\hline \multicolumn{8}{|l|}{ Initial severity classification } \\
\hline severe & $60 \%$ & $42 \%$ & $66 \%$ & $48 \%$ & $68 \%$ & $67 \%$ & $57 \%$ \\
\hline intermediate & $18 \%$ & $34 \%$ & $14 \%$ & $12 \%$ & $16 \%$ & $20 \%$ & $10 \%$ \\
\hline moderate & $16 \%$ & $20 \%$ & $15 \%$ & $36 \%$ & $11 \%$ & $5 \%$ & $21 \%$ \\
\hline unknown & $7 \%$ & $5 \%$ & $5 \%$ & $4 \%$ & $6 \%$ & $7 \%$ & $12 \%$ \\
\hline \multicolumn{8}{|l|}{ Glasgow outcome scale at 6 months } \\
\hline unfavourable & $54 \%$ & $43 \%$ & $58 \%$ & $32 \%$ & $57 \%$ & $44 \%$ & $51 \%$ \\
\hline favourable & $46 \%$ & $57 \%$ & $42 \%$ & $68 \%$ & $43 \%$ & $56 \%$ & $49 \%$ \\
\hline Favourable outcome in severe subset & $37 \%$ & $42 \%$ & $34 \%$ & $51 \%$ & $33 \%$ & $49 \%$ & $35 \%$ \\
\hline
\end{tabular}

UK to $68 \%$ in Spain and Scandinavia, and of those with a moderate injury from $5 \%$ in Scandinavia to $36 \%$ in France. $(\mathrm{p}<0.001)$.

8. The proportion of subjects with a 'favourable' outcome ranged from $42 \%$ in Spain to $68 \%$ in France $(\mathrm{p}=0.001)$.

When analysis was restricted to patients with a 'severe' injury, significant differences remained in type of injury, presence of major extracranial injury, intracranial operation within 24 hours, CT scan findings and presence of subarachnoid haemorrhage, use of invasive monitoring of blood pressure and intracranial pressure, but not in frequency of ventilation. The proportion of favourable outcomes ranged from $33 \%$ in Spain to $51 \%$ in France but this result was now not significantly different across the countries $(\mathrm{p}=0.33)$.

\section{Present and Previous Series of 'Severe Head Injuries'}

There are three previous series, compiled through inter-centre collaboration, of large numbers of patients regarded as having suffered a severe head injury, which invite comparison with the data in severe injuries gained in this study (Table 6).

\section{The International Data Bank}

Jennett and colleagues in 1977 [15] reported the feature of the first 700 cases entered into the so-called 'International Data Bank' from centres in the UK (Glasgow), the Netherlands (Rotterdam and Groningen) and the USA (Los Angeles County Hospital). The series had been collected primarily to investigate the prognosis of coma (no eye opening, no comprehensible verbal response and not obeying commands) known to have persisted for at least 6 hours. Subsequently, these centres were joined by a second USA centre (San Francisco General) and over 18 years a total of 2978 cases were collected. Only limited aspects of the full data set have been reported [28]. We therefore have performed a new analysis and features of the complete series are presented in Table 7.

\section{The USA National Traumatic Coma Data Bank}

Marshall et al. [23] described the organisation of a multicentre study in the USA. Six centres participated in the pilot phase, and four in the subsequent full phase. The criteria for entry was a GCS of 8 or less after non surgical resuscitation, or deteriorating to a 
Table 6. Entry Criteria Applied in Current Study and Three Previous Reports

\begin{tabular}{|c|c|c|c|c|}
\hline & $\begin{array}{l}\text { EBIC core data survey - } \\
\text { severe cases }\end{array}$ & $\begin{array}{l}\text { International data bank full } \\
\text { series }\end{array}$ & $\begin{array}{l}\text { USA traumatic coma data } \\
\text { bank }\end{array}$ & UK four centres study \\
\hline Period & $\begin{array}{l}\text { February } 1995 \text { - April } \\
\quad 1995\end{array}$ & $1968-1985$ & $\begin{array}{l}\text { January } 1984 \text { - September } \\
1987\end{array}$ & $1986-1988$ \\
\hline Age & adult ( $>16$ years) & any & any & any \\
\hline GCS & $\begin{array}{l}\text { severe }(\leq 8) \text { at admission } \\
\text { to NSU. If NSU GCS } \\
\text { not available, at least } \\
\text { one of Pre-Hospital, } \\
\text { A\&E and Post- } \\
\text { resuscitation } \leq 8 \text { and } \\
\text { none }>8 \text {. }\end{array}$ & $\begin{array}{l}\text { coma }(E=1, V \leq 2, M \leq 5) \\
\text { sustained for } 6 \text { hours }\end{array}$ & severe $(\leq 8)$ post-resuscitation & $\operatorname{coma}(E=1, V \leq 2, M \leq 5)$ \\
\hline Time window & $\begin{array}{l}\text { admitted to NSU within } \\
24 \text { hours of injury }\end{array}$ & none & within 48 hours of injury & $\begin{array}{l}\text { admitted to NSU within } 72 \\
\text { hours of injury }\end{array}$ \\
\hline Sample size & 583 & 2978 & $746(+284 \mathrm{GSW}$ or DOA $)$ & 988 \\
\hline
\end{tabular}

GCS of 8 or less. The criteria had to be fulfilled within 48 hours of injury, but the duration that impaired consciousness should be sustained was not specified. Outcome was planned to be assessed at discharge and 6, 12 and 24 months after injury. Foulkes et al. [9] reported the initial features and Marshall et al. [24] the outcome in 746 cases. The numbers actually assessed at the different time points was not stated; time of follow up to last contact for survivors ranged from 11 to 1199 days, with a median of 674 days; two thirds were followed for over 1 year.

\section{The British Four Centre Study}

Murray et al. [30] described 1025 patients collected in the Neurosurgical Units in Glasgow, Edinburgh, Liverpool and Southampton in a study of the clinical application of a prognostic system [2] that had been developed from the data in the International Data Bank. The patients had either been in coma at some time in the neurosurgical unit, including durations of less than 6 hours, or had undergone evacuation of an acute traumatic intracranial haematoma. In a further report Murray et al. [29] described the relationship between intensity of management and outcome in this series. The features of these cases are shown in Table 7.

\section{Findings in Different Series}

The criteria for recruitment to the series are shown in Table 6, demographic and injury characteristics in Table 7, CT scan findings in Table 8, different aspects of management in Table 9, and distribution of outcomes in Table 10. Notable features of these comparisons are considered in the discussion.

\section{Discussion}

The "Core Data Bank Survey" showed that it is feasible to run a major international research project within the framework of the European Brain Injury Consortium, and indeed, the success of the survey was a major factor promoting the constitution of EBIC on a formal basis. The study was inexpensive, as centres were offered minimal funding, and its success depended upon the commitment of the participants. Nevertheless, the data returned were generally of high quality with regard to completeness and credibility of information.

\section{Quality of Data Obtained}

For data in the acute stage, more than $90 \%$ of potential observations were completed and data checking revealed few recordings outside specified ranges or showing obvious inconsistencies requiring referral back to the investigator for clarification. No attempt could be made to confirm the accuracy of the data by comparison with original case records. This process is extremely expensive in time and personnel and is customarily performed only in trials of pharmacological agents conducted with a view to registration with licensing authorities. Nevertheless, the credibility of the data obtained is supported by the internal coherence and consistency of the findings.

For those centres that agreed to provide follow-up, information was obtained from $94 \%$ of their patients, a rate that compares favourably with previous series $[24,35]$.

There was a coherent pattern between cause of injury, pattern of injury sustained and management. 
Table 7. Demographics and Characteristics of Injury in EBIC Survey and Three Previous Series of Severe Head Injuries

\begin{tabular}{|c|c|c|c|c|}
\hline & $\begin{array}{l}\text { EBIC core data survey - } \\
\text { severe cases }\end{array}$ & $\begin{array}{l}\text { International data bank } \\
\text { full series }\end{array}$ & $\begin{array}{l}\text { USA traumatic } \\
\text { coma data bank }\end{array}$ & $\begin{array}{l}\text { UK four centres } \\
\text { study }\end{array}$ \\
\hline Sample size & 583 & 2978 & 746 & 988 \\
\hline Direct admission to neurosurgical hospital & $45 \%$ & not recorded & $61 \%$ & $12 \%$ \\
\hline Age mean & 41 & 36 & - & 34 \\
\hline SD & 20 & 21 & - & 21 \\
\hline median & 35 & 32 & 25 & 29 \\
\hline range & $2-92(10$ aged $\leq 14)$ & $0-89$ & - & $0-87$ \\
\hline interquartile range & $23-58$ & $18-53$ & - & $17-51$ \\
\hline Male & $73 \%$ & $79 \%$ & $77 \%$ & $75 \%$ \\
\hline \multicolumn{5}{|l|}{ Type of injury } \\
\hline motor vehicle occupant & $35 \%$ & $17 \%$ & $64 \%$ & $14 \%$ \\
\hline pedestrian & $13 \%$ & $25 \%$ & $11 \%$ & $30 \%$ \\
\hline RTA other (or unknown) & $9 \%$ & $14 \%$ & - & $13 \%$ \\
\hline work & $5 \%$ & $4 \%$ & - & $4 \%$ \\
\hline assault & $4 \%$ & $7 \%$ & $5 \%$ & $7 \%$ \\
\hline domestic & $11 \%$ & $9 \%$ & - & $9 \%$ \\
\hline sport & $3 \%$ & $2 \%$ & - & $4 \%$ \\
\hline fall under influence of alcohol & $11 \%$ & $14 \%$ & $16 \%$ & $16 \%$ \\
\hline other & $10 \%$ & $8 \%$ & - & $3 \%$ \\
\hline Alcohol involved & not recorded & $35 \%$ & $40 \%$ & not recorded \\
\hline Major extracranial injury & $41 \%$ & $33 \%$ & not recorded & $39 \%$ \\
\hline
\end{tabular}

Table 8. Findings in First CT Scan After Admission in EBIC Survey and Three Previous Reports

\begin{tabular}{|c|c|c|c|c|}
\hline & $\begin{array}{l}\text { EBIC core data survey - } \\
\text { severe cases }\end{array}$ & $\begin{array}{l}\text { International data bank } \\
\text { full series }\end{array}$ & $\begin{array}{l}\text { USA traumatic coma } \\
\text { data bank }\end{array}$ & UK four centres study \\
\hline $\begin{array}{l}\text { Patients with data } \\
\text { Classification }\end{array}$ & 575 & 1263 & 726 & 980 \\
\hline $\begin{array}{l}\text { 1. Diffuse injury without signs of brain } \\
\text { swelling or raised ICP }\end{array}$ & $37 \%$ & $26 \%$ & $32 \%$ & $25 \%$ \\
\hline $\begin{array}{l}\text { 2. Diffuse injury with signs of brain } \\
\text { swelling or raised ICP }\end{array}$ & $15 \%$ & $19 \%$ & $25 \%$ & $12 \%$ \\
\hline 3. Mass lesion: evacuated & $28 \%$ & $37 \%$ & $37 \%$ & $36 \%$ \\
\hline 4. Mass lesion: non-evacuated & $20 \%$ & $18 \%$ & $5 \%$ & $27 \%$ \\
\hline Traumatic subarachnoid haemorrhage & $47 \%$ & not recorded & $39 \%$ & not recorded \\
\hline
\end{tabular}

Table 9. Aspects of Management of Severe Head Injuries in the EBIC Survey and Three Previous Reports

\begin{tabular}{|c|c|c|c|c|}
\hline & $\begin{array}{l}\text { EBIC core data survey - } \\
\text { severe cases }\end{array}$ & $\begin{array}{l}\text { International data bank } \\
\text { full series }\end{array}$ & $\begin{array}{l}\text { USA traumatic coma } \\
\text { data bank }\end{array}$ & UK four centres study \\
\hline Sample size & 583 & 2978 & 746 & 988 \\
\hline $\begin{array}{l}\text { Intracranial operation } \\
\text { (other than burr hole } \\
\text { for ICP monitoring) }\end{array}$ & $37 \% *$ & $47 \%$ & $33 \%$ & $39 \%$ \\
\hline Ventilated & $92 \%$ & $45 \%$ & - & $66 \%$ \\
\hline ICP monitored & $43 \%$ & $35 \%$ & - & $31 \%$ \\
\hline $\begin{array}{l}\text { Arterial pressure } \\
\text { monitored }\end{array}$ & $80 \%$ & not recorded & - & $36 \%$ \\
\hline
\end{tabular}

* Within first 24 hours after injury.

Thus, patients injured in a road vehicle accident more often had complications associated with high velocity injury, for example major extracranial injuries and an extracranial operation, and more often had complica- tions of hypoxia and hypotension. Likewise, in common with previous reports $[11,12,43]$, they less often had an intracranial mass lesion requiring an operation. There was also coherence between the pattern of in- 
Table 10. Glasgow Outcome Scale at six Months of Subjects Reported in the EBIC Survey and Three Previous Series

\begin{tabular}{|c|c|c|c|c|}
\hline & $\begin{array}{l}\text { EBIC core data survey - } \\
\text { severe cases }\end{array}$ & $\begin{array}{l}\text { International data bank } \\
\text { full series }\end{array}$ & $\begin{array}{l}\text { USA traumatic coma } \\
\text { data bank }\end{array}$ & UK four centres study \\
\hline Sample size & 481 & 2959 & 746 & 976 \\
\hline \multicolumn{5}{|l|}{ Glasgow outcome scale } \\
\hline dead & $40 \%$ & $49 \%$ & $36 \%$ & $39 \%$ \\
\hline vegetative & $4 \%$ & $2 \%$ & $5 \%$ & $1 \%$ \\
\hline severe disability & $16 \%$ & $13 \%$ & $16 \%$ & $17 \%$ \\
\hline moderate disability & $19 \%$ & $15 \%$ & $16 \%$ & $16 \%$ \\
\hline good recovery & $21 \%$ & $20 \%$ & $27 \%$ & $24 \%$ \\
\hline $\begin{array}{l}\text { moderate/good } \\
\text { (unspecified) }\end{array}$ & - & - & - & $3 \%$ \\
\hline $\begin{array}{l}\text { "Favourable" outcome } \\
\text { (moderate disability } \\
\text { or good recovery) }\end{array}$ & $40 \%$ & $35 \%$ & $43 \%$ & $42 \%$ \\
\hline $\begin{array}{l}\text { Severe disability in } \\
\text { survivors }\end{array}$ & $29 \%$ & $27 \%$ & $27 \%$ & $28 \%$ \\
\hline
\end{tabular}

jury reported to have been observed in the CT scan and the recording of performance of an intracranial operation.

\section{Severity of Injury}

This is the first report of a large prospective series of patients in neurotrauma centres that incorporates subjects considered to have either a moderate or a severe injury.

Although interrelationships would be expected between severity of injury features such as investigation findings, complications, management and outcome, in practice it proved difficult to apply either well established simple distinctions between severe and moderate injury or more refined discriminations. This was as a result of the frequent unavailability of information due to the use of sedation and paralysis, a problem reported by other workers [22]. Although this was least often a problem in observations recorded before arrival at hospital, data from this phase were not available for a third of subjects. Even when 'prehospital' clinical state is available it can be a misleading index of prognosis [45]. Conversely, data were available for almost all subjects at the "within hospital" time points but the yield of information was offset by the substantial portion of unassessable items. The high proportion of patients in whom a full GCS could not be obtained at the time of admission to the neurosurgical or neurological unit illustrates the potential problem in using clinical responsiveness at this stage as an inclusion criterion for trials.

The time points and clinical data chosen as a basis for categorising severity of head injury in previous studies have varied considerably [22]. Time points include: on arrival at hospital [10], or at the neurosurgical department [3], after completion of 'nonsurgical' resuscitation [23, 27, 46], within four hours of injury [25] or the persistence of features of impaired consciousness for intervals of from six hours $[4,15,31$, $36]$ to 12 hours [8], 24 hours [1], 48 hours [9, 23] and 72 hours [30]. Approaches used to allow for missing data have included allocating a 'pseudo score' of 1 for the verbal portion of the GCS in an intubated patient [23], but this results in a loss of information in severe cases $[17,33]$ and may be especially misleading in moderate injuries.

We found it was neither appropriate nor valid to apply a categorisation of severity on the basis of information at any specific single time point. The approach we devised took maximum advantage of whatever information was available from each of the four time points and enabled us objectively to allocate categories of severe, intermediate or moderate to $94 \%$ of patients reported. We could then use these groups to relate to other data obtained from the whole series, to compare patients in different geographical areas, and to relate findings from this study to previous reports.

The group we subsequently classified as severe proved to be younger, more often had been injured as a motor vehicle occupant, were more often directly admitted to hospital with a neurosurgical unit and more often had an major extracranial injury. Their CT scans were less often normal and more often showed swelling, subarachnoid haemorrhage and intracranial mass lesions. They more often had an intracranial operation 
and more often received intensive management by the use of ventilation and invasive monitoring of blood pressure and intracranial pressure.

Characterisation of groups by the method we used to classify initial severity was also reflected in differences in outcome. Mortality in those classified as moderate or intermediate was less than in the severe cases and there was a corresponding increase in the proportion categorised as an independent, 'favourable outcome'. Nevertheless, it was noteworthy that disability was common in all classes of severity. Indeed, the proportions of individuals categorised as severely or moderately disabled did not differ significantly across the spectrum of early severity, being $36 \%, 32 \%$, $38 \%$ and $38 \%$ respectively in the severe, intermediate, moderate and unclassified groups.

The coherence of patterns observed in the different groups provided a reasonable background to investigate the patterns observed in the different regions in the current survey and to relate the present findings to previous reports.

\section{Geographical Variations}

The survey was not planned as a comprehensive, rigorous, epidemiological study, completely representative of the practice of head injury care in the different countries. Nevertheless, in the large number of participating centres and the large number of total patients reported, significant differences in patients and practice were observed that merit cautious comment. In order to avoid focusing on individual centres, we grouped units either according to countries or, where the numbers of patients reported were too small, into larger geographical units.

The findings in different areas present a complex pattern, but certain points can be noted. There were broad similarities among Italy, Spain and Benelux countries in terms of the patients having a relatively younger age distribution, a high occurrence of injury as a vehicle occupant, with associated major extracranial injuries, and frequent admission directly to a hospital with a neuro unit. The proportions of subjects judged to be severe were also high in Italy and Spain and outcome was less often favourable in Spain, Italy and Benelux countries, in all cases and in the severe subset. The Scandinavian subjects, and to some extent those in Germany, were similar to those in Spain, Italy and Benelux in terms of frequency of severe injury but were less often multiply injured and were more often transferred secondarily to the hospital with the neurosurgical unit, and more often had an intracranial operation. In the $U K$ and France subjects were relatively older, but less often a vehicle occupant, were most often transferred to the neurosurgical unit from another hospital, had a low rate of major extracranial injury and of intracranial operation, were less often 'severe' and had a higher rate of favourable outcome.

Underlying some of these variations appeared to be differences in the proportion of patients taken directly to a hospital with a neurosurgical unit or transferred, presumably selectively, after initial assessment and management in another hospital, and along with this, differences in patterns of injury and severity of brain damage of patients in neurosurgical units in different countries. Differences in approach to management are being analysed further and, since this study, guidelines for use in Europe have been published [19].

\section{Comparison with Previous Series}

The present and the three previous series referred to contain a total of 5,717 patients with head injury treated in a neuroscience unit. For detailed analysis we have focused on those patients in the present series graded as having a severe injury $(\mathrm{n}=583)$, for whom outcome was known in 481 . The comparisons made show many similarities but also differences that may, in part, reflect variations in criteria for recruitment to the different series and also changes in management over the last three decades.

\section{Demography}

Very similar proportions of patients in the four series were male $(73-79 \%)$. The proportions injured in a road traffic accident were very similar in the original International Data Bank, in the UK Four Centres study and the current survey $(56-57 \%)$ whereas in the North American series many more $(75 \%)$ received their injury as a result of a road traffic accident. The proportions with major associated extracranial injuries were similar (33-41\%) in the International Data Bank and the UK and European surveys; these data were not reported for the North American study (Table 7).

Demographically, the most clear distinction between the present and previous series was in the age of the subjects. In the EBIC survey, the entry criteria specified an age of 16 years or older and as a consequence, the median age was 35 years whereas in the 
North American Coma Data Bank, the median age was 25 years, and was 32 in the International and 29 in the UK surveys, in which respectively $18 \%$ and $21 \%$ patients were aged 15 years or less. The focus on adults in the EBIC survey reflected the interest in studies of pharmacological interventions, from which children are customarily excluded.

Comparison of the CT scan findings in the different series is hindered by changing approaches to classification of scan that have evolved over the last two decades, indeed, many of the first 700 patients in the International Data Bank were studied before CT scanning was available. Recognition of the importance of radiological signs of cerebral compression and raised intracranial pressure (obliteration of the third ventricle and basal cisterns) [37, 41, 42] and of traumatic subarachnoid haemorrhage [6] has increased the focus on these items in more recent series.

A 'mass' lesion was present in between $42 \%$ of subjects in the American series to $63 \%$ of the UK cases (Table 8 ). This high proportion in the latter may reflect the arrangements for selective admission of severe injuries seen in the UK study. The proportion of patients considered to have a diffuse injury complicated by swelling or shift differed between the North American $(25 \%)$ and present European series (12\%), which classified findings according to the same system. One explanation for the difference may be observer variation in CT scan interpretation [7]. Another is uncertainty about exactly when the classification is applied; this was not specified in the North American series and in some subjects may have been applied taking findings in later CT scans into account. In the present series classification was made prospectively, on the first CT scan and this may account for the lower occurrence of signs of secondary swelling and raised ICP. On the other hand traumatic subarachnoid haemorrhage was reported more frequently in the current series; perhaps reflecting greater appreciation of the significance of this finding and the interest of treatment of subarachnoid haemorrhage by pharmacological methods $[6,13,16,18]$.

\section{Management and Complications}

Around one third of the patients underwent an early intracranial operation in the present, the UK and North American series (33-39\%) but this was performed in $47 \%$ in the International series (Table 9). This difference may reflect recruitment to the Interna- tional survey having required coma to persist for more than 6 hours, or may reflect changing referral policy, with more patients not directly requiring neurosurgical operation being referred to neurotrauma units.

There were clear variations in aspects of 'medical' management in the different series. Ventilation, used in only $24 \%$ of the original 700 patients in the International Data Bank, was employed in $45 \%$ of the full series, $66 \%$ in the subsequent UK series and in $92 \%$ in patients the present survey. Although the use of invasive arterial monitoring was not recorded in the earlier series, it rose from $36 \%$ in the UK study to $80 \%$ of severe cases in the European survey. In contrast, there was less difference in the frequency with which intracranial pressure was reported to be monitored: $35 \%$ of subjects in the International Data Bank, $31 \%$ in the UK study, and $43 \%$ in the current survey. Conversely there was decreasing use of corticosteroids and data on this was not even recorded in the European survey. The rates of utilisation of ventilation and of monitoring of ICP are not stated in the reports of the North American Traumatic Coma Data Bank.

The observed incidence of hypotension $(22 \%)$ is lower than the incidences reported from the Traumatic Coma Data Bank (29\% [32] and 30\% [5]). It is slightly higher than the $15 \%$ reported from the recent International Tirilazed study [25] which considered only events in the first four hours. In the current series, the reported incidence of hypoxia is very similar $(27 \%)$ to the report from the Traumatic Coma Data Bank (26\%) [5]; in the International Tirilazad trial the incidence in the first four hours was again lower (15\%) [25].

\section{Outcome}

Outcome was broadly similar in the North American, UK and present European series. Mortality ranged from $36-40 \%$, and favourable outcome from $40-43 \%$ (Table 10 ). The higher mortality in the full International Data Bank (49\%) presumably reflects these patients having been more severely injured because they were in coma for at least 6 hours. However, this difference was restricted to mortality and the distributions of outcomes in survivors was remarkably similar across the different series. Thus, just over one quarter of survivors were severely disabled and between $35 \%$ and $43 \%$ of the overall population had a favourable outcome. This observation supports the view that the major influence of initial severity may be on mortality and that, if survival occurs, disability is 
much more difficult to predict from early features. It also supports the consistency of the Glasgow Outcome Scale in describing distribution of outcome in large series; its consistency when applied to individual subjects [21] has been improved recently by a new structured method [44].

\section{Conclusion}

It has proved possible, with minimal resources, to conduct an observational study providing a large amount of data, of apparently high quality, about severely and moderately head injured adults treated in major European neurotrauma centres. The data show broad consistency in the features of such patients across Europe and between the findings in this and previous series. Nevertheless the study has also shown several differences and highlights the need for caution in making comparisons between patients studied either at different times or in different regions.

Two major sources of differences in reported series of head injuries are aspects of organisation and management concerning referral and admission policy and variations in causes, patterns and severity of brain damage and extracranial injures of subjects in different centres. This difference in management policies and arrangements for neurosurgical services leads to different proportions of patients being either transported directly to a hospital with a neurosurgical centre or referred selectively after admission and assessment in another hospital. These influences are readily analysed whereas the problems encountered in analysing patterns of severity within this series of patients and previous series have highlighted the difficulties in applying classifications of early severity, as a result of the loss of observations occasioned by the use of sedation and ventilation. Further analyses are in progress, concerning variations in injury pattern, severity, management and outcome. An observational study, even performed prospectively and to a high degree of quality, can be expected to provide no more than tentative conclusions and hypothesis for further study.

A major conclusion of the present study is that definitive information, upon which to base decisions about the choice of different systems of management, is still likely to result only from data obtained in prospective, rigourously controlled investigations. The success of the survey shows that the European Brain Injury Consortium is potentially well founded to meet the challenge of performing such investigations, in pursuit of its goal of improving the treatment of head injured patients.

\section{Acknowledgements}

We are very grateful to the investigators in the centres participating in the core survey for their cooperation in the collection of the data reported. These investigators are listed in the appendix. We are also grateful to the investigators in the previous series which have been reviewed here for allowing us to include previously unreported data Professor B. Jennett, Professor Dr. J. Minderhoud, Professor T. Kurze, Dr. L. Pitts, Professor J. Pickard, Mr. D. Shaw, Professor J. D. Miller. We are also pleased to acknowledge the role of Mrs. M. Naismith, EBIC Administrator, for liaison with study sites.

\section{List of Investigators}

\section{Listed by centre}

Belgium: L. Vannerem, Brugge; T. van der Kerckhove, Gent. Denmark: J. Haase, Aalborg; F. Gjerris, Copenhagen.

Finland: J. Ohman, Helsinki.

France: P. Frerebeau, Montpellier; F. Lapierre, Poitiers; P. Rousseaux, Reims; J. Lagarrigue, Toulouse.

Germany: D. Kintzel, Berlin (Friedrichshain); J. Zierski, Berlin (Neukölln); A. Unterberg, Berlin (Virchow Klinikum); F. Oppel, Bielefeld; G. Schackert, Dresden; W. E. Hassler, Duisburg; W. Bock, Düsseldorf; D. Stolke, Essen; D. K. Böker, Giessen; H. P. Richter, Günzburg; M. Westphal, Hamburg; E. Rickels, Hannover; W. I. Steudel, Homburg/Saar; R. Kallf, Jena; A. Karimi, Köln; P. Schmiedek, Mannheim; K. von Wild, Münster; A. T. Brawanski, Regensburg; R. Schönmayr, Wiesbaden.

Italy: F. Rasulo/N. Latronico, Brescia; F. Servadei, Cesena; G. Tomei/N Stocchetti, Milano (Maggiore); Giovanelli/L. Beretta, Milano (San Raffaele); S. Gaini/G. Citerio, Monza; Nizzoli/Paprella, Parma; G. Brambilla/Braschi, Pavia; F. Della Corte/M. Scerrati, Roma; Faccani/M. Berardino, Torino; G. Trincia/A. Paolin, Treviso.

The Netherlands: S. Egeler-Peerdeman, Amsterdam (Free University); H. Haaxma-Reiche, Groningen; A. Maas, Rotterdam; C. A. F. Tulleken, Utrecht:

Spain: J. Sahuquillo, Barcelona; R. Lobato, Madrid; J. Garibi, Vizcaya.

Sweden: J. Hillman, Linkoping; C. H. Nordstrom, Lund; G. Algers, Umea; L. Persson, Uppsala.

Switzerland: R. W. Seiler/S. Godoy, Bern; H. G. Imhof/R. Bernays, Zurich.

United Kingdom: G. Cruikshank, Birmingham; R. J. Nelson, Bristol; J. D. Pickard, Cambridge; R. Hatfield, Cardiff; M. Choksey, Coventry; D. Gentleman, Dundee; P. Andrews, Edinburgh; G. Teasdale, Glasgow; M. Dearden, Leeds; M. Rice-Edwards, London (Charing Cross); A. D. Mendelow, Newcastle; D. T. Hope, Nottingham; J. Mohan, Plymouth; C. H. Davis, Preston; F. Iannotti, Southampton. Yugoslavia: Djordjevic, Belgrade.

\section{References}

1. Bailey I, Bell A, Gray J, Gullan R, Heiskanan O, Marks PV, Marsh H, Mendelow DA, Murray G, Ohman J et al (1991) A trial of the effect of nimodipine on outcome after head injury. Acta Neurochir (Wien) 110: 97-105 
2. Barlow P, Murray L, Teasdale GM (1987) Outcome after severe head injury - the Glasgow model. In: WA Corbett (ed) Medical applications of microcomputers. John Wiley \& Sons Ltd, pp 105-126

3. Becker DP, Miller JD, Ward JD, Gienberg R, Young HF, Sakalus R (1977) The outcome from severe head injury with early diagnosis and intensive management. J Neurosurg 47: 491-502

4. Bowers SA, Marshall LF (1980) Outcome in 100 consecutive cases of severe head injury treated in San Diego: a prospective analysis. J Neurosurg 6: 237-242

5. Chesnut RM, Marshall LF, Klauber MR, Blunt BA, Baldwin N, Eisenberg HM, Jane JA, Marmarou A, Foulkes MA (1993) The role of secondary brain injury in determining outcome from severe head injury. J Trauma 34: 216-222

6. Eisenberg H, Gary HE Jr, Aldrich EF et al (1990) Initial CT findings in 753 patients with severe head injury. A reports from the NIH Traumatic Coma Data Bank. J Neurosurg 73: 688-698

7. El Tabou M, Knill-Jones RD, Teasdale GM (1995) Reliability of interpretation of CT scan of head injured patients. J Neurotrauma 12: 488

8. European Study Group on Nimodipine in Severe Head Injury (1994) A multicentre trial of the efficacy of Nimodipine on outcome after severe head injury. J Neurosurg 80: 797-804

9. Foulkes MA, Eisenberg HM, Jane JA, Marmarou A, Marshall LF, and the Traumatic Coma Data Bank Research Group (1991) The Traumatic Coma Data Bank: design, methods and baseline characteristics. J Neurosurg 75: S8-S13

10. Gaab MR, Trost HA, Alcantara A, Karimi-Nejad A, Moskopp D, Schultheiss R, Bock WJ, Piek J, Klinge H, Scheil F, Ostwerwald P, Samii M, Brawanski A, Meixensberger J, Schürmann K, Schubert R, Arnold H, Kehler U, Deisenroth K, Benker G, Vester JC, Dietz H (1994) 'Ultrahigh' dexamethasone in acute brain injury. Results from a prospective randomized doubleblind multicenter trial. Zentralbl Neurochir 55: 135-143

11. Gennarelli TA (1983) Head injury in man and experimental animals. Clinical aspects. Acta Neurochir [Suppl] (Wien) 32: 1

12. Gentleman D, Teasdale G, Murray L (1986) Cause of severe head injury and risk of complications. Br Med J (Clin Res Ed) 292 (6518): 449

13. Harders A, Kakarieka A, Braakman R and the German and Subarachnoid Haemorrhage Study Group (1996) Traumatic subarachnoid haemorrhage and its treatment with Nimodipine. J Neurosurg 85: 82-89

14. Jennett B, Bond M (1975) Assessment of outcome after severe brain damage. A practical scale. Lancet 1: 480-484

15. Jennett B, Teasdale G, Galbraith S, Pickard J, Grant H, Braakman R, Avezaat C, Maas A, Minderhoud J, Vecht CJ, Heiden J, Small R, Caton W, Kurze T (1977) Severe head injuries in three countries. J Neurol Neurosurg Psychiatry 40: 291-298

16. Kakarieka A, Braakman R, Schakel EH (1994) Clinical significance of the finding of subarachnoid blood on CT after head injury. Acta Neurochir (Wien) 129: 1-5

17. Koziol JA, Hacke W (1990) Multivariate data reduction by principal components with application to neurological scoring systems. J Neurol 237: 416-464

18. Langham J, Goldfrad C, Teasdale GM, Shaw D, Rowan K (1998) Assessing the effect of calcium channel blockers in patients with acute traumatic brain injury on mortality and neurological disability. (Cochrane review) The Cochrane Library, issue 3, Update Software, Oxford

19. Maas AIR, Dearden M, Teasdale GM, Braakman R, Cohadon F, Iannotti F, Karimi A, Lapierre F, Murry G, Ohman J,
Persson L, Servadei F, Stocchetti N, Unterberg A (on behalf of the European Brain Injury Consortium) (1997) EBIC guidelines for management of severe head injury in adults. Acta Neurochir (Wien) 139: 286-294

20. Maas AIR, Steyerberg EW, Murray GD, Bullock R, Baethmann A, Marshall LF, Teasdale GM (1998) Why have recent trials of neuroprotective agents in head injury failed to show convincing efficacy? A pragmatic analysis and theoretical considerations. Neurosurgery (submitted)

21. Maas AR, Braakman R, Schouten JA, Minderhoud JM, van Someren AH (1983) Agreement between physicians on assessment of outcome following severe head injury. J Neurosurg 58: 321-325

22. Marion DW, Carlier PM (1994) Problems with initial Glasgow coma scale assessment caused by prehospital treatment of patients with head injuries: results of a national survey. $\mathrm{J}$ Trauma 336: 89-95

23. Marshall LF, Becker DP, Bowers SA, Cayard C, Eisenberg H, Gross CR, Grossman RG, Jane JA, Kunitz SC, Rimel R, Tabaddor K, Warren J (1983) The National Traumatic Coma Data Bank Part 1. Design, purpose, goals and results. J Neurosurg 59: 276-284

24. Marshall LF, Gautille T, Klauber M, Eisenberg H, Jane JA, Luerssen TG, Marmarou A, Foulkes M (1991) The outcome of severe closed head injury. J Neurosurg 75: S28-36

25. Marshall LF, Maas AIR, Marshall SB et al (1998) A multicentre trial on the efficacy of using Tirilazed Mesylate in cases of head injury. J Neurosurg 89: 519-525

26. Marshall LF, Marshall SB, Klauber MR et al (1991) A new classification of head injury based on computerized tomography. J Neurosurg 75: S14-20

27. Miller JD, Butterworth JF, Gudeman SK, Faulkner JE, Choi SC, Selhurst JB, Harbison JW, Lutz HA, Young HF, Becker DP (1981) Further experience in the management of severe head injury. J Neurosurg 54: 289-299

28. Murray GD (1986) Use of an international data bank to compare outcome following severe head injury in different centres. Stat Med 5: 102-112

29. Murray LS, Teasdale GM, Murray GD, Miller DJ, Pickard JD, Shaw MDM (1998) Head injuries in four British neurosurgical centres. Br J Neurosurg (submitted)

30. Murray LS, Teasdale GM, Murray GD, Jennett B, Miller JD, Pickard JD, Shaw MDM, Achilles J, Bailey S, Jones P, Kelly D, Lacey J (1993) Does prediction of outcome alter patient management? Lancet 341: 1487-91

31. Nordström CH, Sundbarg GG, Messeter K, Schalen W (1989) Severe traumatic brain lesions in Sweden, part 2; impact of aggressive neurosurgical intensive care. Brain Injury 3: 267-281

32. Piek J, Chesnut RM, Marshall LF, Berkum-Clark M, Klauber MR, Blunt BA, Eisenberg HM, Jane JA, Marmarou A, Foulkes MA (1992) Extracranial complications of severe head injury. J Neurosurg 77: 901-907

33. Prasad K (1996) The Glasgow coma scale: a critical appraisal of its clinimetric properties. J Clin Epidemiol 49: 755-763

34. Rimel RW, Giordani B, Barth JT, Jane JA (1982) Moderate head injury: completing the clinical spectrum of brain trauma. J Neurosurg 11: 344-351

35. Scheibel RS, Levin HS, Clifton GL (1998) Completion rates and feasibility of outcome measures: experience in a multicentre clinical trial of systemic hypothermia for severe head injury. J Neurotrauma 15: 685-692

36. Stuart GG, Merry GS, Smith JA, Yelland JD (1983) Severe head injury managed without intracranial pressure monitoring. J Neurosurg 59: 601-603 
37. Teasdale E, Cardoso E, Galbraith S, Teasdale G (1984) CT scan in severe diffuse head injury: physiological and clinical correlations. J Neurol Neurosurg Psychiatry 47: 600-603

38. Teasdale GM, Braakman R, Cohadon F et al (1997) The European Brain Injury Consortium. Nemo solus satis sapit: nobody knows enough alone. Acta Neurochir (Wien) 139: 797 803

39. Teasdale GM, Jennett B (1974) Assessment of coma and impaired consciousness. Lancet 2: 81-84

40. Teasdale GM, Murray G, Parker L, Jennett B (1979) Adding up the Glasgow coma score. Acta Neurochir [Suppl] (Paris) 1: 28: $13-16$

41. Toutant S, Klauber M, Marshall L, Toole B, Bowers S, Seelig J, Varnell J (1984) Absent or compressed basal cisterns on first CT scan; ominous predictors of outcome in severe head injury. $\mathrm{J}$ Neurosurg 61: 691-694

42. Van Dongen K, Braakman R, Gelpke G (1983) The prognostic value of computerised tomography in comatose head injured patients. J Neurosurg 59: 951-957

43. Volmer DG, Torner JC, Eisenberg HM (1991) Age and outcome following traumatic coma: why do older patients fare worse? J Neurosurg 75: S37-S49

44. Wilson JTL, Pettigrew LEL, Teasdale GM (1998) Structured interviews for the Glasgow Outcome Scale and the Extended Glasgow Outcome Scale: guidelines for their use. J Neurotrauma 15: 8: 573-585
45. Windler JV, Rosen P, Altry ES (1984) Prehospital use of the Glasgow Coma Scale in severe head injury. J Emer Med 2: 1-6

46. Young B, Runge JW, Waxman KS, Harrington T, Wilberger J, Muizelaar JP, Boddy A, Kupiec JW (1996) Effects of pegorgotein on neurologic outcome of patients with severe head injury. A multicentre, randomised, controlled trial. JAMA 276: 538543

\section{Comment}

This is a multi-authored, multi-institutional survey of the current treatment of head injury in Europe and Britain. It is contrasted with the North American Traumatic Coma Data Bank and the International Data Bank which involves the UK, the Netherlands, and the USA. Differences in triage and early management are reflected. This is good baseline information from which other papers will be derived.

The survey includes over 1000 patients gathered from over 50 institutions. The data are not contaminated by pharmacologic trials. Copies of the EBIC questionnaire are available from Professor Murray on request.

Julian T. Hoff

Correspondence: Professor Gordon D. Murray, Medical Statistics Unit, University of Edinburgh Medical School, Teviot Place, Edinburgh, EH8 9AG, UK. 